is seen as becoming a socially competent person in a second culture without losing the same competence in his or her culture of origin. However, new concepts of biculturalism and bicultural identity are emerging that are relevant to globalisation. Traditional definitions imply migration processes, either voluntary or forced, as in the case of refugees. Migrant individuals then form ethnic minorities, while different pathways towards biculturalism take place among specific communities. However, if globalisation can be conceptualised as 'a compression of time and space', biculturalism should be considered in the absence of peoples' geographical displacement.

Some authors argue that most people around the world will develop a different form of bicultural identity, combining their local identity with an identity linked to the global culture. This phenomenon is particularly relevant in adolescents, as contemporary urban teenagers worldwide tend to follow similar consumption patterns and do not have memories of times when their ancestral culture was preserved from globalisation (Arnett, 2002). This new form of biculturalism could be both an opportunity for personal fulfilment and a source of identity confusion. Factors influencing these possible outcomes one way or the other should be integrated in cultural psychiatry research agendas.

Arnett, J. J. (2002) The psychology of globalization. American Psychologist, 57, 774-783.

Bhugra, D. \& Mastrogianni, A. (2004) Globalisation and mental disorders. Overview with relation to depression. British Journal of Psychiatry, 184, 10-20.

LaFromboise, T., Coleman, H. L. K. \& Gerton, J. (1993) Psychological impact of biculturalism: evidence and theory. Psychological Bulletin, II4, 395-412.

A. Eytan Geneva University Hospitals, Department of Psychiatry, 2, Ch du Petit-Bel-Air 1225, Geneva, Switzerland

\section{Humanity and biology in psychiatry}

Further to our previous letter (Owen et al, 2003) we are writing to respond to $\mathrm{Dr}$ Turner's assertion (Turner, 2003) that biological psychiatrists secretly want to take the humanity out of the humanities. This highlights a conceptual division within psychiatry and one partisan misunderstanding that stymies the debate.

It can be argued that academic psychiatrists are divided into two camps. The first is those who were drawn to the higher functioning of the brain as a conceptual frontier, and see logicodeductive empirical methodology as leading to the accumulation of universally applicable valid evidence. The second is those who were attracted to psychiatry (often away from other branches of medicine) because of its shared space with the humanities. The latter group focus on the difficulties of applying scientific method to the interpretation of meanings and intentions, emphasising cultural relativity, and issues of power and politics.

Highlighting the above division is not new. What we suggest is that the proponents of both camps, by their unwillingness to engage with or understand the field of the other, risk conceptual disaster at both extremes.

The argument from the humanities is of relevance to any scientist. The late-20th century critique of the hubris, historicism and relativity of science strikes at the core of the assumptions of biological psychiatry. Unfortunately, it is an argument that many do not even feel to be relevant. This seems to be an opinion based largely on a lay view that anything within the humanities is of little utility.

This is the very hubris that leads to the name-calling that Dr Turner exemplifies in his response to our perceived 'biological' letter. However, this assumption, among many in the humanities, that the biological psychiatrists are all washed up - applying a suspect statistical method in suspect circumstances - has led to them dangerously disengaging from any medical aspect of their profession. If our assertion is right, and this is a motivation for coming to psychiatry in the first place, this is hardly surprising.

The worrying thing is, of course, that despite the shortcomings of current approaches to categorisation, aetiology and treatment, mental illness does exist, and hence psychiatry has a role to play in its understanding and treatment. Our job, if we remain interested in being doctors, is to see (based on what evidence we have) where the medical model can add to the care of someone mentally unwell.

If this is hopeless, as some (e.g. Szasz, 1960) have argued, then what are we doing in psychiatry? Given this position, the responsibility for looking after the mentally unwell is surely better handed to others. The irony is that many of the most nihilistic psychiatrists prescribe psychotropics; either this amounts to extreme hypocrisy, or the methodology and results of biological research do matter after all.

With biological research becoming increasingly specialised and complex, a new technology will only be understood by relatively few. In the humanities, the language remains esoteric and hard for the uninitiated to engage with. If the proponents from both ends of the debate do not see the worth in the others' business, when will the results or arguments of one ever be valid for the other?

In essence, in response to Turner's assertion (2003) that biological psychiatrists wish to take the humanity out of the humanities, we fear that he hints at a desire within the humanities to take the medical science out of psychiatry. If this is the position, then we fear a psychiatrist is left adding nothing to the multidisciplinary team other than personal opinion. Although much empirical research is burdened with vested interests, criticised for not being conscious enough of its assumptions, and maladapted to studying the profound experimental suffering we see in mental illness, it remains the only way to replace opinion with anything more certain.

The humanities help us to see what mental illness is, but there will always be an accompanying biology and we have always known that modulating the biology can modulate the illness. If we value the treatment of mental illness, we must value both humanistic and biological investigations.

Owen, G., Tulloch, A., Harland, R., et al (2003) Scientific psychiatry? (letter). British Journal of Psychiatry, 183, 564 .

Szasz, T. S. (1960) The myth of mental illness. American Psychologist, 15, II3-118.

Turner, M. A. (2003) Scientific psychiatry (author's reply). British Journal of Psychiatry, 183, 565.

R. Harland, G. Owen, M. Broome PO 67, Institute of Psychiatry, De Crespigny Park, London SE5 8AF, UK. E-mail: m.broome@iop.kcl.ac.uk

\section{Heroic, not disordered: creativity and mental illness revisited}

Dr Wills (2004) assumes that I have overlooked Jamison's 1993 work. In fact, the hyperbolic Touched with Fire only compounds the research problems of her original (1989) study. No matter how many famous artists she collects to 'prove' her case, there is no triumph in finding so much disturbance when your self-selected 
sample is padded with it, giving scant or no attention to creative people who manage to be both prolific and stable. Jamison (1993) herself warns that 'labeling as manicdepressive anyone who is unusually creative, accomplished, energetic, intense, moody or eccentric both diminishes the notion of individuality in the arts and trivializes a very serious, often deadly illness' (p. 8) yet she proceeds to do precisely that Blurring the distinction between serious bipolar disorder and cyclothymia, with chapter titles like 'Their Life a Storm Whereon They Ride' she relies heavily on the overblown anguish of Romantic poets to hammer her case home. This makes thrilling reading, but it is not science.

As for those 'many academic studies... over the past century' (Wills, 2004), Jamison is more likely to drop names than disclose content in the attempt to build a historical pedigree for her work. Lombroso, to whom she refers most often, claimed that people of high ability were small, pasty and emaciated, with irregular teeth (1895). Unfortunately, since readers are about as likely to consult the original Lombroso (or Nisbet or Moreau) as they are to scrutinise Jamison's methods, the delusion persists that there is long-standing empirical weight behind the notion of the 'mad' creative person

Dr Wills finds Ludwig's statistics (1995) acceptable, but I have difficulty with imprecise variables such as 'any problem' of parents and siblings, one of the few significant differences found between the families of creative artists and others and even these, Ludwig himself admits, are 'very weak' (Ludwig, 1995: p. 157). And how does one measure 'non-conformity', 'odd behavior' or 'anger at mother' with any precision or reliability?

Although Wills thinks psychological autopsies are worthy tools, their validity is compromised by dependence on self-reports and second- and third-hand accounts, biographers' natural tendency to shape the story around their opinions of their subjects, and clear experimenter bias - after all, the determined user of psychological autopsy can discover 'madness' in anyone's life. Jamison uses such 'evidence' of mental illness as 'possibly transient hypomanic episodes' (p. 199), interest in spiritualism, spendthrift tendencies, and vague gossip: 'thought by others to have had at least a trace of insanity' (p. 168).

Finally, Wills declares that my view of the creative person (Schlesinger, 2002) is naïve, as well as Laingian in its denial. I do not claim that bipolar disorder does not exist, only that there is no hard scientific evidence that creative people are more likely to suffer from it. As for my concerns being passé - reflecting the 'antipsychiatry movement of the 1960s and 1970s' - the news is that objection to reckless labelling never disappeared. It is actually growing, particularly in the USA, where even the general public has noticed the link between elastic diagnoses and pharmaceutical profits. And I make no apologies for believing creative people to be heroic - especially when so many assume they are mentally disordered.

Jamison, K. R. (1989) Mood disorders and patterns of creativity in British writers and artists. Psychiatry, $\mathbf{5 2}$. 125-134.

Jamison, K. R. (1993) Touched with Fire: Manic Depressive Illness and the Artistic Temperament. New York: Free Press.

Lombroso, C. (1895) The Man of Genius. London: Walter Scott.

Ludwig, A. M. (1995) The Price of Greatness: Resolving the Creativity and Madness Controversy. New York: Guilford Press.

Schlesinger, J. (2002) Issues in creativity and madness. Part two: Eternal flames. Ethical Human Sciences and Services: An International Journal of Critical Inquiry, 4 139-142.
Wills, G. (2004) Creativity and mental health (author's reply). British Journal of Psychiatry, 184, |84-185.

J. Schlesinger 300 Broadway, Suite 3B, Dobbs Ferry, New York 10522, USA

\section{The case report on the way out?}

I read with interest the farewell editorial by Professor Wilkinson (2003), in which he reflects on his tenure as Editor of the Journal. $\mathrm{He}$ is to be congratulated for both his leadership as an accomplished Editor of one of the world's most reputable psychiatry journals and for his thought-provoking 'last words'. Although I agree with almost everything in the editorial, I am troubled by his statement, 'I hastened the demise of the case report, to exclude what I see as psychiatric trivia'. Is this downgrading of the case report justified? Have case reports become trivia? Is the case report on the way out? The answer to these questions is 'no'. At a time of widespread unfilled academic positions in many sub-specialties (including psychiatry), decreasing research potential and resources (and hence limited research income and recognition), the case report remains a valuable source of new (and important) clinical information. Before we reject the case report, remember it was once said, 'We don't like their sound, and guitar music is on the way out' (Decca Recording Co., rejecting the Beatles, 1962).

Wilkinson, G. (2003) Fare thee well - the Editor's last words. British Journal of Psychiatry, I82, 465-466.

K. M. Kuczkowski Department of

Anesthesiology, UCSD Medical Center, 200 W.

Arbor Drive, San Diego, CA 92103-8770, USA.

E-mail: k.kuczkowski@ucsd.edu

\section{One hundred years ago}

\section{Is epilepsy a functional disease? [extract]}

IN the Journal of Nervous and Mental Disease for March Professor Allen M. Starr of New York draws attention to the importance of having a correct view regarding epilepsy. In medical text-books from the earliest times epilepsy has been classed as a functional disease and this view does not seem to have been questioned seriously. Yet a careful review of facts ascertained recently, says Professor Starr, seems to demonstrate the fallacy of the prevailing opinion and to prove conclusively "epilepsy is usually, if not always, an organic disease". This conclusion is based upon a careful study of 2000 cases of epilepsy which have been seen personally and of which satisfactory records were kept. In the first place it was found possible to draw a fairly 